\title{
Quantitative detection of TIMP-3 promoter hypermethylation and its prognostic significance in esophageal squamous cell carcinoma
}

\author{
ITASU NINOMIYA ${ }^{1}$, KAZUYUKI KAWAKAMI ${ }^{2}$, SACHIO FUSHIDA ${ }^{1}$, TAKASHI FUJIMURA ${ }^{1}$, \\ HIROSHI FUNAKI ${ }^{1}$, HIROYUKI TAKAMURA ${ }^{1}$, HIROHISA KITAGAWA ${ }^{1}$, HISATOSHI NAKAGAWARA ${ }^{1}$, \\ HIDEHIRO TAJIMA $^{1}$, MASATO KAYAHARA ${ }^{1}$ and TETSUO OHTA ${ }^{1}$
}

\begin{abstract}
${ }^{1}$ Gastroenterologic Surgery, Department of Oncology, Division of Cancer Medicine, Graduate School of Medical Science and ${ }^{2}$ Division of Translational and Clinical Oncology, Molecular and Cellular Targeting Translational Oncology Center, Cancer Research Institute, Kanazawa University, Kanazawa, Ishikawa 920-8641, Japan
\end{abstract}

Received July 2, 2008; Accepted September 5, 2008

DOI: 10.3892/or_00000170

\begin{abstract}
Tissue inhibitor of metalloproteinase-3 (TIMP-3) has an inhibitory effect on tumor development, growth and metastasis due to its interaction with matrix metalloproteinases (MMPs). We investigated the prognostic significance of TIMP-3 gene promoter methylation in esophageal squamous cell carcinoma (ESCC). TIMP-3 methylation was analyzed by MethyLight, a quantitative and methylation-specific PCR method. Hypermethylation was found in 9/51 (18\%) surgically resected ESCC samples and was associated with reduced disease-free $(p=0.0039)$ and overall survival $(p=0.0047)$. Upon multivariate analysis, it was found to be an independent prognostic parameter for poor survival and was associated with earlier recurrence after surgery $(\mathrm{p}=0.0238)$, especially via pleural dissemination ( $\mathrm{p}=0.001$ ). Expression levels for TIMP-3 protein and for several MMPs were analyzed by Western blot analysis in 20 pairs of ESCC and adjacent normal tissue. The expression of MMP-2, -7 and -9 proteins in tumor tissue was significantly higher than in corresponding normal mucosa ( $\mathrm{p}=0.0051,0.0064$ and 0.0004 , respectively). In contrast, the expression of TIMP-3 protein in tumor tissue was significantly lower than in matched normal mucosa $(\mathrm{p}=0.0152)$. Tumors with TIMP-3 hypermethylation expressed lower levels of TIMP-3 protein compared to those without hypermethylation $(\mathrm{p}=0.0357)$. These results demonstrate that TIMP-3 hypermethylation is associated with lower TIMP-3 protein
\end{abstract}

Correspondence to: Dr Itasu Ninomiya, Gastroenterologic Surgery, Department of Oncology, Division of Cancer Medicine, Graduate School of Medical Science, Kanazawa University, 13-1, Takaramachi, Kanazawa, Ishikawa 920-8641, Japan

E-mail: nino@surg2.m.kanazawa-u.ac.jp

Key words: esophageal carcinoma, squamous cell carcinoma, TIMP-3, hypermethylation, prognostic factor expression in ESCC and with poor patient survival due to a high frequency of recurrence by pleural dissemination.

\section{Introduction}

Esophageal carcinoma is one of the most common types of cancer and is associated with unfavorable patient survival due to the high proportion of patients that present with advanced stage disease. Recent progress in surgical procedure has allowed radical lymph node dissection in esophageal cancer (1). However, postoperative local and distant recurrence is still a major problem in the management of this cancer $(2,3)$. Although our general understanding of the mechanisms of cancer development and progression have improved, the molecular and biological data relating to esophageal cancer are still quite limited and poorly understood. The identification of good prognostic markers in esophageal cancer remains of major importance for improving the clinical management and outcome of patients with this disease.

Matrix metalloproteinases (MMPs) are a group of $\mathrm{Ca}^{2+}$ dependent, zinc-containing enzymes that degrade proteins in the extracellular matrix (4). More than 25 MMPs have been described to date and are classified on the basis of amino acid homology, peptide structure and in vitro substrate specificity. MMPs are implicated in all aspects of tumor progression; they enhance tumor-induced angiogenesis, destroy local tissue architecture to allow tumor growth, and break down basement membranes during the process of metastatic spread. The expression of MMP-1, -2, -3, -7, -9, -11 and -13 and membrane-type MMPs (MT-MMPs) and their prognostic significance in esophageal squamous cell carcinoma (ESCC) has been reported previously $(5,6)$. The activity of MMPs is regulated at the transcriptional level by cytokines and growth factors and by proenzyme activation or tissue inhibitors of MMP (TIMPs) following their secretion $(7,8)$. There are four known TIMPs that complex with, and thus inactivate, both latent and active MMPs. TIMP-3 is a secreted $24-\mathrm{kDa}$ glycoprotein produced by most cell types. Because of differences in function and tissue localization, the abrogation of the function 
of TIMP-3 during tumorigenesis may be a more important event than that of other members of the TIMP family. TIMP-3 is insoluble and remains bound to the extracellular matrix, unlike other TIMP family members such as TIMP-1 and -2 which are soluble inhibitors. TIMP-3 inhibits the activity of MMP-1, -2, -3, -9 and -13 (9), as well as the activity of MT-MMPs (10). It can also exert inhibitory effects on tumor progression via anti-angiogenic activity and the promotion of apoptosis (11-14). Decreased expression of TIMP-3 could therefore favor tumor growth by reducing the inhibition of MMPs and apoptotic activity and by increasing angiogenesis.

The hypermethylation of gene promoters has been highlighted recently as a mechanism for gene inactivation during the development of several tumor types (15). TIMP-3 is silenced in association with aberrant promoter hypermethylation in cell lines derived from human cancers (16). Previous studies showed a high incidence of TIMP-3 hypermethylation in Barret's esophagus and in esophageal adenocarcinoma $(17,18)$. Reduced TIMP-3 protein expression in esophageal adenocarcinoma was associated with more advanced disease and poor patient survival (18). An immunohistochemical study showed that reduced TIMP-3 protein expression correlated with less favorable survival in ESCC patients (19). Together, these findings suggest that TIMP-3 hypermethylation may be of clinical use as a prognostic factor due to its role in silencing gene expression. Little is known, however, regarding the silencing effect of TIMP-3 hypermethylation on gene expression and its prognostic significance in ESCC. In this study, we used a quantitative, high-throughput methylation assay, MethyLight, to investigate the frequency and clinical importance of TIMP-3 hypermethylation in 51 cases of ESCC $(17,20,21)$. Furthermore, we examined TIMP-3 gene hypermethylation in relation to the expression level of TIMP-3 protein in ESCC.

\section{Materials and methods}

Tissue samples. Fifty-one tissue specimens of primary ESCC and 38 tissue specimens from adjacent normal esophageal mucosa were obtained from patients who underwent surgery at Kanazawa University Hospital. Tissues were immediately frozen in liquid nitrogen and kept at $-80^{\circ} \mathrm{C}$ until use. All samples were diagnosed histopathologically as ESCC. No preoperative radiotherapy or chemotherapy had been performed for any of the cases. The clinicopathological characteristics were evaluated according to the guidelines of the Union Internationale Contre le Cancer.

DNA extraction and sodium bisulfite conversion. Genomic DNA was extracted from tissues using standard proteinase-K digestion and phenol-chloroform extraction methods (22). Sodium bisulfite conversion of genomic DNA was performed as described previously (23).

Methylation analysis. Following sodium bisulfite conversion of DNA, the methylation analysis was performed by a fluorescence-based, real-time PCR assay (MethyLight) as described previously $(17,20,21,24)$. Two sets of primers and probes, designed specifically for bisulfite-converted DNA, were used: a methylated set for the TIMP-3 gene and a reference set for $\beta$-actin to normalize for input DNA (17). The reference primers and the probe for $\beta$-actin gene amplification were designed for a region of the $\beta$-actin gene that has no $\mathrm{CpG}$ dinucleotides, thus allowing for equal amplification regardless of methylation levels (17). The percentage of fully methylated molecules at the TIMP-3 gene promoter was calculated by dividing the TIMP-3: $\beta$-actin ratio of Sss-Itreated control DNA from normal esophageal mucosa and multiplying by 100 . Samples containing $70 \%$ fully methylated molecules were designated as hypermethylated. The $70 \%$ cutoff value for the TIMP-3 methylation level was determined from the mean plus standard deviation of the TIMP-3 methylation level in normal mucosa which provided the best discrimination between favorable and poor survival according to tumor TIMP-3 methylation status.

Western blot analysis. The expression of TIMP-3 protein and several MMPs in 20 sets of ESCC tissue and corresponding normal esophageal mucosa was examined by Western blot analysis. Primary rabbit anti-human TIMP-3 polyclonal antibody was obtained from Chemicon (Temecula, CA). Anti-hMMP-1, -2, -7 and -9 monoclonal antibodies were obtained from Fuji Chemical Industries Ltd. (Takaoka, Japan). Cellular protein was extracted from fresh frozen tissue in lysis buffer [20 mM Tris- $\mathrm{HCl}$ (pH 7.4), 0.1\% SDS, $1 \%$ Triton $\mathrm{X}-100,1 \%$ sodium deoxycholate and $0.2 \%$ protease inhibitor cocktail (Sigma, St. Louis, MO)]. Solubilized protein $(20 \mu \mathrm{g})$ in lysis buffer was denatured in loading buffer containing $40 \mathrm{mM}$ DTT and electrophoresed in a 5-15\% gradient SDS-polyacrylamide gel. After electrophoresis, the proteins were transferred to polyvinylidene difluoride membranes and incubated with primary antibody at a dilution of 1:2000. Horseradish peroxidase-conjugated and affinitypurified anti-rabbit immunoglobulin for TIMP-3 and anti-mouse immunoglobulin for MMPs (1:5000 dilution; Chemicon) were used as the secondary antibodies. The membrane was developed using a chemiluminescence system (ECL detection reagents; Amersham, Aylesbury, UK). To evaluate the relative amounts of protein in each lane, $\beta$-actin served as an internal control and was measured with anti$\beta$-actin monoclonal antibody (Sigma; 1:5000 dilution). The immunoreactivity of each lane was measured by densitometry using image analysis software (NIH Image version 1.61). The ratio of protein level in tumor tissue to that in corresponding normal esophageal mucosa was calculated from the signal intensities. The relative magnitude of the signal for expression of each protein was standardized to that of $\beta$-actin as the internal control.

Statistical analysis. TIMP-3 methylation status was assessed for associations with clinicopathological features using the Mann-Whitney $U$ test for depth of invasion and histological grade and the $\chi^{2}$ two-tailed test for the remaining parameters. MMP and TIMP-3 protein expression levels were compared between normal mucosa and carcinoma tissue using the Wilcoxon signed-rank test. The relative intensity of TIMP-3 protein expression in carcinoma tissue compared to corresponding normal esophageal mucosa and according to TIMP-3 methylation status was analyzed by the MannWhitney U test. Overall and disease-free survivals were 
Table I. Association of TIMP-3 hypermethylation with clinicopathological parameters.

\begin{tabular}{|c|c|c|c|}
\hline \multirow[b]{2}{*}{ Variable/category } & \multicolumn{2}{|c|}{$T I M P-3$ hypermethylation } & \multirow[b]{2}{*}{$\begin{array}{c}\text { Statistical } \\
\text { significance } \\
\text { (p) }\end{array}$} \\
\hline & $\begin{array}{c}\text { Negative } \\
(n=42)\end{array}$ & $\begin{array}{c}\text { Positive } \\
\quad(n=9)\end{array}$ & \\
\hline \multicolumn{4}{|l|}{ Depth of invasion } \\
\hline $\mathrm{T} 1$ & 4 & 0 & 0.4997 \\
\hline $\mathrm{T} 2$ & 6 & 1 & \\
\hline $\mathrm{T} 3$ & 31 & 7 & \\
\hline $\mathrm{T} 4$ & 1 & 1 & \\
\hline \multicolumn{4}{|c|}{ Lymph node metastasis } \\
\hline Negative & 14 & 1 & 0.2514 \\
\hline Positive & 28 & 8 & \\
\hline \multicolumn{4}{|l|}{ Distant metastasis } \\
\hline Negative & 37 & 8 & $>0.9999$ \\
\hline Positive & 5 & 1 & \\
\hline \multicolumn{4}{|l|}{ Histological grade } \\
\hline G1 & 9 & 2 & 0.6742 \\
\hline $\mathrm{G} 2$ & 21 & 4 & \\
\hline G3 & 11 & 2 & \\
\hline G4 & 1 & 1 & \\
\hline
\end{tabular}

calculated using the Kaplan-Meier method and compared by the Log-rank test. The prognostic significance of various parameters tested in multivariate analysis was determined by forward Cox regression analysis. Statistical analyses were performed using SPSS II for Windows (SPSS Japan, Tokyo Japan). A p-value $<0.05$ was considered significant.

\section{Results}

TIMP-3 hypermethylation. Hypermethylation of the promoter region of TIMP-3 was analyzed by quantitative methylationspecific PCR (MethyLight). The average and standard deviation of TIMP-3 methylation levels in normal mucosa and carcinoma tissue were $35.5 \pm 35.9$ and $72.7 \pm 226 \%$, respectively. When TIMP-3 methylation was classified according to a $70 \%$ cutoff value, hypermethylation was found in 6/36 (17\%) normal mucosal samples and 9/51 (18\%) carcinoma tissue samples from ESCC patients. None of the 9 cases showing TIMP-3 hypermethylation in carcinoma tissue showed TIMP-3 hypermethylation in the corresponding normal esophageal mucosa.

The relationships between TIMP-3 hypermethylation in tumor tissue and clinicopathological parameters are listed in Table I. No significant correlations were observed between TIMP-3 hypermethylation and clinicopathological parameters in ESCC. However, patients with TIMP-3 hypermethylation had significantly poorer prognosis compared to those without. This was observed for both disease-free $(p=0.0039)$ and overall survival $(\mathrm{p}=0.0047)$ (Fig. 1A and B). Upon univariate analysis, the significant prognostic variables for predicting
A

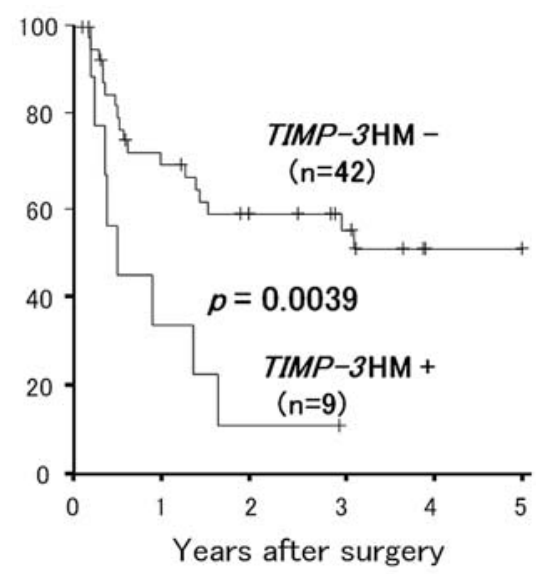

B

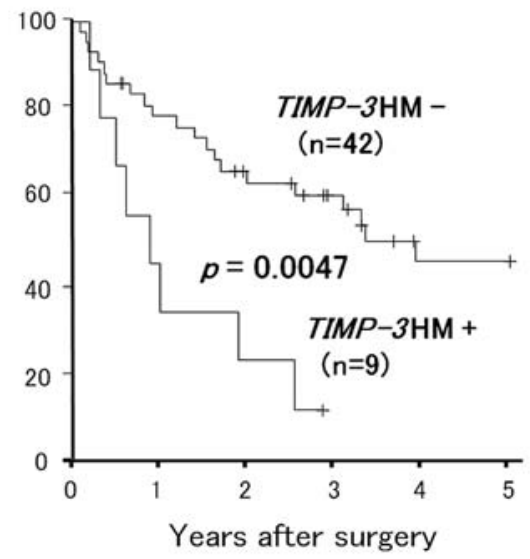

Figure 1. Postoperative disease-free (A) and overall (B) survival curves for 51 ESCC patients classified according to TIMP-3 methylation status. Patients with TIMP-3 hypermethylation $\left(\mathrm{HM}^{+}\right)$had significantly reduced disease-free $(\mathrm{p}=0.0039)$ and overall $(\mathrm{p}=0.0047)$ survival compared to those without $\left(\mathrm{HM}^{-}\right)$.

disease-free and overall survival were TIMP-3 hypermethylation and distant metastasis. When TIMP-3 hypermethylation and four clinicopathological parameters which are widely considered as prognostic indicators (depth of invasion, lymph node metastasis, distant metastasis, histological grade) were evaluated using multivariate analysis, TIMP-3 hypermethylation emerged as an independent prognostic factor for both disease-free and overall survival (Tables II and III). Patients with TIMP-3 hypermethylation showed twice the rate of recurrence compared to those without (89 vs. $43 \%$, $\mathrm{p}=0.0238$ ) (Table IV). As shown in Table IV, tumors with TIMP-3 hypermethylation showed a strong predilection $(5 / 9$, $55 \%)$ for pleural dissemination $(\mathrm{p}=0.001)$.

Western blot analysis. Representative results of the Western blot analysis for MMP and TIMP-3 protein expression are shown in Fig. 2. Anti-MMP-1, -2, -7 and -9 antibodies recognized latent and active forms of each molecule with the following sizes: 52 (latent form) and $42 \mathrm{kDa}$ (active form), 72 (latent form) and $62 \mathrm{kDa}$ (active form), 28, 92 (latent form) and $66 \mathrm{kDa}$ (active form), respectively. Immunoreactive bands in the lower molecular-weight region are presumably the result of degradation products. Anti-TIMP-3 polyclonal antibody recognized a band of $52 \mathrm{kDa}$ which corresponds to the dimerized form of TIMP-3 protein. 
Table II. COX regression analysis for disease-free survival.

\begin{tabular}{|c|c|c|c|c|c|c|}
\hline \multirow[b]{2}{*}{ Variable } & \multicolumn{3}{|c|}{ Univariate analysis } & \multicolumn{3}{|c|}{ Multivariate analysis } \\
\hline & HR & $95 \% \mathrm{CI}$ & $\mathrm{p}$ & HR & $95 \% \mathrm{CI}$ & $\mathrm{p}$ \\
\hline $\begin{array}{l}\text { TIMP-3 hypermethylation } \\
\text { Negative, Positive }\end{array}$ & 3.292 & $1.397-7.756$ & 0.006 & 3.548 & $1.487-8.468$ & 0.004 \\
\hline $\begin{array}{l}\text { Distant metastasis } \\
\text { Negative, Positive }\end{array}$ & 3.639 & $1.426-9.282$ & 0.007 & 3.969 & $1.537-10.25$ & 0.004 \\
\hline $\begin{array}{l}\text { Depth of invasion } \\
\text { T1-2, T3-4 }\end{array}$ & 2.279 & $0.782-6.638$ & 0.131 & & $\mathrm{n} / \mathrm{a}$ & \\
\hline $\begin{array}{l}\text { Lymph node metastasis } \\
\text { Negative, Positive }\end{array}$ & 1.766 & $0.709-4.401$ & 0.222 & & $\mathrm{n} / \mathrm{a}$ & \\
\hline $\begin{array}{l}\text { Histological grade } \\
\text { G1-2, G3-4 }\end{array}$ & 0.902 & $0.379-2.149$ & 0.816 & & $\mathrm{n} / \mathrm{a}$ & \\
\hline
\end{tabular}

HR, hazard ratio; CI, confidence interval; n/a, not applicable.

Table III. COX regression analysis for overall survival.

\begin{tabular}{|c|c|c|c|c|c|c|}
\hline \multirow[b]{2}{*}{ Variable } & \multicolumn{3}{|c|}{ Univariate analysis } & \multicolumn{3}{|c|}{ Multivariate analysis } \\
\hline & HR & $95 \% \mathrm{CI}$ & $\mathrm{p}$ & HR & $95 \% \mathrm{CI}$ & $\mathrm{p}$ \\
\hline $\begin{array}{l}\text { TIMP-3 hypermethylation } \\
\text { Negative, Positive }\end{array}$ & 3.237 & $1.370-7.650$ & 0.007 & 3.765 & $1.561-9.083$ & 0.003 \\
\hline $\begin{array}{l}\text { Distant metastasis } \\
\text { Negative, Positive }\end{array}$ & 3.598 & $1.403-9.228$ & 0.008 & 4.308 & $1.639-11.324$ & 0.003 \\
\hline $\begin{array}{l}\text { Depth of invasion } \\
\mathrm{T} 1-2, \mathrm{~T} 3-4\end{array}$ & 2.085 & $0.793-5.481$ & 0.136 & & $\mathrm{n} / \mathrm{a}$ & \\
\hline $\begin{array}{l}\text { Lymph node metastasis } \\
\text { Negative, Positive }\end{array}$ & 2.047 & $0.831-5.044$ & 0.120 & & $\mathrm{n} / \mathrm{a}$ & \\
\hline $\begin{array}{l}\text { Histological grade } \\
\text { G1-2, G3-4 }\end{array}$ & 0.928 & $0.409-2.105$ & 0.858 & & $\mathrm{n} / \mathrm{a}$ & \\
\hline
\end{tabular}

HR, hazard ratio; CI, confidence interval; n/a, not applicable.

Densitometric analysis for 20 matched tumor and normal tissue samples showed that expression levels for MMP-2, -7 and -9 protein were significantly higher in tumor tissue compared to corresponding normal mucosa $(\mathrm{p}=0.0051$, 0.0064 and 0.0004 , respectively) (Fig. 3A-C). The expression level for MMP-1 protein in tumor tissue did not differ with that in the corresponding normal mucosa. In contrast to the MMPs, the expression level for TIMP-3 protein in tumor tissue was significantly lower than in corresponding normal mucosa ( $\mathrm{p}=0.0152$ ) (Fig. 3D). Hypermethylation of TIMP-3 was present in the tumor DNA of 7 of the 20 cases investigated for protein expression. These showed significantly lower levels of TIMP-3 expression in tumor tissue compared to cases without TIMP-3 hypermethylation ( $\mathrm{p}=0.0357)$ (Fig. 4).

\section{Discussion}

All ESCC patients in this study underwent curative resection with lymph node dissection at the time of surgery. The small subgroup of cases with TIMP-3 hypermethylation (18\%) showed a significantly higher rate of recurrence and reduced survival after surgery compared to cases without hypermethylation of this gene. Furthermore, TIMP-3 hypermethylation emerged as an independent prognostic factor for both disease-free and overall survival in multivariate analysis that included the conventional prognostic variables. In preliminary studies we investigated the frequency and clinical relevance for the hypermethylation of 15 genes thought to be important in cancer development and progression. These were 
Table IV. Recurrent site after surgery according to TIMP-3 gene methylation status.

TIMP-3 hypermethylation

$\begin{array}{ccc}\begin{array}{c}\text { Negative } \\ (\mathrm{n}=42)\end{array} & \begin{array}{c}\text { Positive } \\ (\mathrm{n}=9)\end{array} & \begin{array}{c}\text { Statistical } \\ \text { significance }\end{array}\end{array}$

(p)

Patients with recurrence $18(42.9 \%) \quad 8(88.8 \%) \quad 0.0238$

Recurrent site

Local

$2(4.7 \%) \quad 0 \quad(0.0 \%) \quad>0.9900$

Distant organ

$11(26.2 \%) \quad 4(44.4 \%)$

0.4840

Lymph node

$6(14.3 \%) \quad 1(11.1 \%)$

$>0.9900$

Pleural cavity

$2(4.8 \%) \quad 5(55.5 \%)$

0.0010

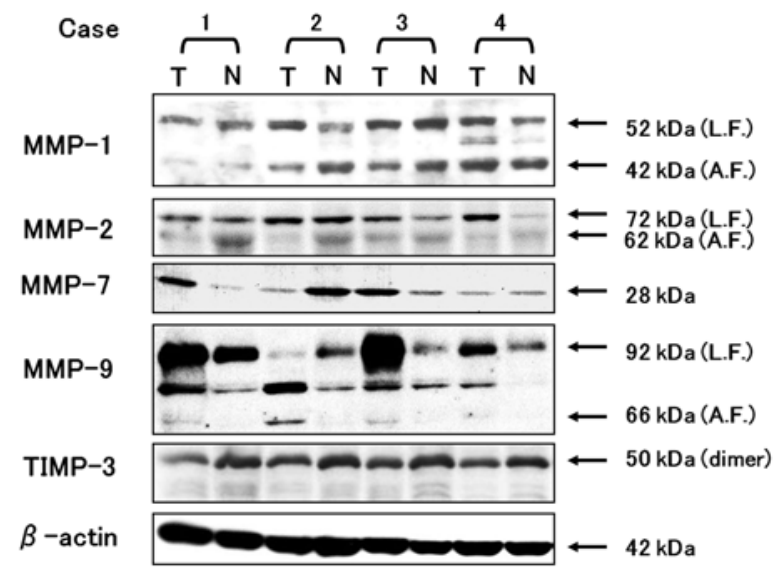

Figure 2. Western blot analysis of MMPs and TIMP-3 protein in representative tissue samples of esophageal carcinoma $(\mathrm{T})$ and corresponding normal esophageal mucosa $(\mathrm{N})$. The molecular weights $(\mathrm{kDa})$ of immunoreactive bands are shown at the right. Increased expression of MMP-2, -7 and -9 proteins and reduced expression of TIMP-3 protein in several tumor tissue samples relative to corresponding normal mucosa is evident. A.F., active form; L.F., latent form.

Adenomatous polyposis coli,p14, Calcitonin, E-cadherin, p16, p15, Death-associated protein kinase, Estrogen receptor $\alpha$, Glutathione S-transferase $\pi$, Hypermethylated in cancer, 06methylguanine-DNA methyltransferase, Mut L Homolog 1, Myogenic determinant 1 and Thrombospondin 1 as well as the TIMP-3 gene. With the exception of TIMP-3 hypermethylation, no prognostic significance was found for any of the methylated genes examined in 37 cases of ESCC (data not shown). Further large-scale clinical studies are required to validate the clinical significance of TIMP-3 hypermethylation observed for ESCC in this study.

We found that TIMP-3 protein expression in primary ESCC tissue was reduced in association with hypermethylation of TIMP-3 (Fig. 4). Previously, Bachman et al (16) demonstrated that TIMP-3 expression was silenced in association with aberrant $5^{\prime}$ promoter-region methylation in cell lines derived from human cancers. They also found aberrant methylation of TIMP-3 in primary cancers of the kidney, brain, colon, breast and lung, but not in any of 41
A

MMP-2

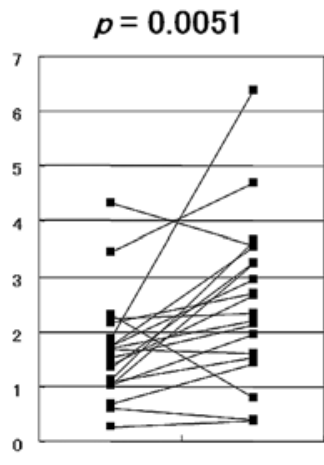

N

$\mathrm{T}$

C
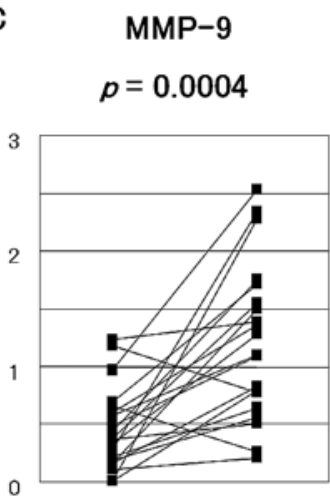

$\mathrm{N}$

T
B $\quad$ MMP-7

$p=0.0064$

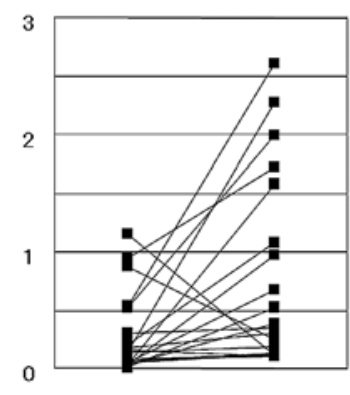

N

$\mathrm{T}$
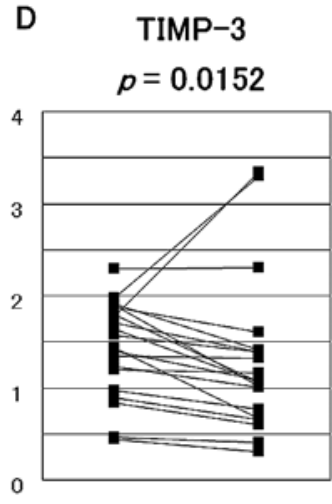

$\mathrm{N}$

T

Figure 3. Expression levels for MMP and TIMP-3 protein in matching normal and tumor tissues from 20 ESCC cases. Signals for MMP-2 (A), -7 (B), -9 (C) and TIMP-3 (D) proteins were measured and standardized to that of $\beta$-actin as an internal control. Signals from tumor tissue (T) are compared to the matching normal esophageal mucosa $(\mathrm{N})$. Expression levels for MMP-2, -7 and -9 protein in tumor tissue were significantly higher than in corresponding normal mucosa ( $\mathrm{p}=0.0051,0.0064$ and 0.0004 , respectively). In contrast, the expression level of TIMP-3 protein was significantly lower in tumor tissue compared to matching normal mucosa $(\mathrm{p}=0.0152)$.

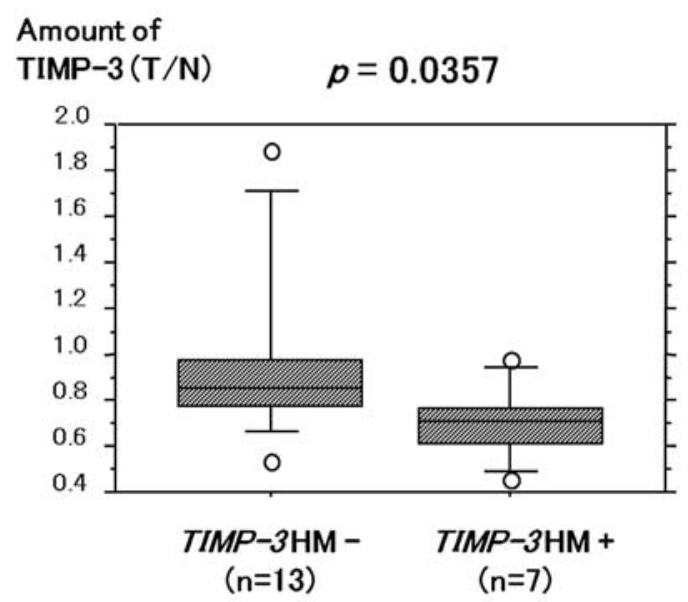

Figure 4. Correlation of TIMP-3 protein expression with TIMP-3 gene methylation status. The ratio of TIMP-3 expression in tumors relative to the matching normal esophageal mucosa $(\mathrm{T} / \mathrm{N})$ tissues was compared according to TIMP-3 methylation status. Cases with TIMP-3 hypermethylation $\left(\mathrm{HM}^{+}\right)$ $(\mathrm{n}=7)$ showed significantly lower levels of TIMP-3 expression in tumor tissue compared to cases without $\left(\mathrm{HM}^{-}\right)(\mathrm{n}=13)(\mathrm{p}=0.0357)$. 
normal tissue samples. These researchers concluded that methylation-associated silencing of TIMP-3 is tumor specific. Based on the non-quantitative methylation-specific PCR method, Darnton et al (18) reported the absence of TIMP-3 methylation in normal esophageal mucosa. Eads et al (24) developed a real-time, quantitative TaqMan assay with methylation-specific PCR and named this high-throughput, fluorescence-based assay MethyLight. Using this assay, they examined methylation patterns during the progression of esophageal adenocarcinoma (17). They reported that $19 \%$ of normal esophageal mucosal samples showed TIMP-3 hypermethylation. However, TIMP-3 methylation was observed to be more frequent in intestinal metaplasia, dysplasia and adenocarcinoma compared to normal esophageal mucosa.

We also examined TIMP-3 methylation in normal esophageal tissue by MethyLight and found that $17 \%$ of our samples were positive. Since MethyLight is a quantitative and highly sensitive method, it is important to determine the best cutoff level allowing good distinction between hypermethylation and hypomethylation. Eads et al (17) reported that a $4 \%$ cutoff value for fully methylated molecules gave the best discrimination between normal and premalignant/ malignant tissues. In the present study, our aim was to investigate the prognostic significance of TIMP-3 methylation in ESCC. Consequently, the $70 \%$ cutoff value used here corresponds to the mean plus standard deviation of TIMP-3 methylation in normal mucosa which resulted in the best discrimination between favorable and poor survival according to tumor TIMP-3 methylation status. It is important to note that significantly reduced TIMP-3 protein expression was noted in cases showing $>70 \%$ of TIMP-3 molecules methylated (Fig. 4).

In addition to TIMP-3 hypermethylation and the reduction of TIMP-3 protein, elevated expression of its MMP target proteins was observed in ESCC tissue relative to corresponding normal mucosa. The expression level of MMPs did not have any relation to the TIMP-3 methylation status. Expression of MMPs and TIMPs has been shown not only in malignant cells but also in stromal fibroblast-like cells and macrophages located within tumors (25). Immunohistochemical staining has shown that TIMP-3 protein is expressed in normal squamous epithelium and in macrophages or leukocytes in the underlying lamina propria $(18,19)$. TIMP-3 protein expression in tumor tissue is heterogeneous, with reduced expression at the invasive front of ESCC. Western blot assay is therefore suitable for the semi-quantitative analysis of MMP and TIMP expression in tumor tissues with mixed stromal and neoplastic components. Our analysis with non-microdissected whole tissue showed increased expression of MMPs and decreased expression of TIMP-3 in ESCC compared to normal tissue (Fig. 3). These alterations in MMP and TIMP-3 expression may cause an imbalance in proteolytic activity. Increased proteolytic activity would be expected to facilitate primary tumor growth, angiogenesis, invasion and metastasis.

A previous immunohistochemical study showed that reduced expression of TIMP-3 protein correlated with depth of invasion, number of lymph node metastases, infiltrative growth pattern and disease stage of ESCC (19). In the present study, TIMP-3 methylation status did not correlate with any of the clinicopathological parameters examined. However, an increased rate of recurrence via pleural cavity dissemination was noted in cases with TIMP-3 hypermethylation. When these tumors express little or no TIMP-3, increased activity of MMPs may follow, resulting in a more aggressive phenotype for invasion and metastasis and subsequent poor patient outcome (26). High levels of MMP expression in tumor tissue was a consistent finding in the present study (Fig. 3A-C). Cancer cells with TIMP-3 hypermethylation might therefore have an increased capacity to destroy the basement membrane of pleura and thus allow pleural dissemination.

In conclusion, TIMP-3 methylation might be a clinically useful biomarker for predicting patient survival following surgery for ESCC. It could provide stronger prognostic information than conventional clinicopathological parameters, particularly after curative resection for advanced stage disease. Furthermore, TIMP-3 hypermethylation might be a good epigenetic target for cancer treatment. The post-surgical application of a histone deacetylase inhibitor targeting the hypermethylated TIMP-3 promoter region might reduce the incidence of recurrence by pleural dissemination. Determination of the TIMP-3 methylation status can therefore provide a useful prognostic tool in ESCC and can also indicate the need for further treatment modalities following surgery.

\section{References}

1. Akiyama H, Tsurumaru M, Udagawa $H$ and Kajiyama $Y$ : Radical lymph node dissection for cancer of the thoracic esophagus. Ann Surg 220: 364-373, 1994.

2. Matsubara T, Ueda M, Takahashi T, Nakajima T and Nishi M: Localization of recurrent disease after extended lymph node dissection for carcinoma of the thoracic esophagus. J Am Coll Surg 182: 340-346, 1996.

3. Bhansali MS, Fujita H, Kakegawa T, Yamana H, Ono T, Hikita S, Toh Y, Fujii T, Tou U and Shirouzu K: Pattern of recurrence after extended radical esophagectomy with three-field lymph node dissection for squamous cell carcinoma in the thoracic esophagus. World J Surg 21: 275-281, 1997.

4. Nagase $\mathrm{H}$ and Woessner JF Jr: Matrix metalloproteinases. J Biol Chem 274: 21491-21494, 1999.

5. Shima I, Sasaguri Y, Kusukawa J, Yamana H, Fujita H, Kakegawa T and Morimatsu M: Production of matrix metalloproteinase- 2 and metalloproteinase- 3 related to malignant behavior of esophageal carcinoma. A clinicopathologic study. Cancer 70: 2747-2753, 1992.

6. Gu Z-D, Li J-Y, Li M, Gu J, Shi X-T, Ke Y and Chen K-N: Matrix metalloproteinases expression correlates with survival in patients with esophageal squamous cell carcinoma. Am J Gastroenterol 100: 1835-1843, 2005.

7. Sato H, Kida Y, Mai M, Endo Y, Sasaki T, Tanaka J and Seiki M: Expression of genes encoding type IV collagen-degrading metalloproteinases and tissue inhibitors of metalloproteinases in various human tumor cells. Oncogene 7: 77-83, 1992.

8. Chakraborti S, Mandal M, Das S, Mandal A and Chakraborti T: Regulation of matrix metalloproteinases: an overview. Mol Cell Biochem 253: 269-285, 2003.

9. Apte SS, Olsen BR and Murphy G: The gene structure of tissue inhibitor of metalloproteinases (TIMP)-3 and its inhibitory activities define the distinct TIMP gene family. J Biol Chem 270: 14313-14318, 1996.

10. Zhao H, Bernardo MM, Osenkowski P, Sohail A, Pei D, Nagase H, Kashiwagi M, Soloway PD, DeClerck YA and Fridman R: Differential inhibition of membrane type 3 (MT3)matrix metalloproteinase (MMP) and MT1-MMP by tissue inhibitor of metalloproteinase (TIMP)-2 and TIMP-3 regulates pro-MMP-2 activation. J Biol Chem 279: 8592-8601, 2004.

11. Bian J, Wang Y, Smith MR, Kim H, Jacobs C, Jackman J, Kung HF, Colburn NH and Sun Y: Suppression of in vivo tumor growth and induction of suspension cell death by tissue inhibitor of metalloproteinases (TIMP)-3. Carcinogenesis 17: 1805-1811, 1996. 
12. Baker AH, George SJ, Zaltsman AB, Murphy G and Newby AC: Inhibition of invasion and induction of apoptotic cell death of cancer cell lines by overexpression of TIMP-3. Br J Cancer 79: $1347-1355,1999$

13. Anand-Apte B, Pepper MS, Voest E, Montesano R, Olsen B, Murphy G, Apte SS and Zetter B: Inhibition of angiogenesis by tissue inhibitor of metalloproteinase-3. Invest Ophthalmol Vis Sci 38: 817-823, 1997.

14. Ahonen M, Baker AH and Kahari VM: Adenovirus-mediated gene delivery of tissue inhibitor of metalloproteinases-3 inhibits invasion and induces apoptosis in melanoma cells. Cancer Res 58: 2310-2315, 1998

15. Das PM and Singal R: DNA methylation and cancer. J Clin Oncol 22: 4632-4642, 2004

16. Bachman KE, Herman JG, Corn PG, Merlo A, Costello JF, Cavenee WK, Baylin SB and Graff JR: Methylation-associated silencing of the tissue inhibitor of metalloproteinase- 3 gene suggests a suppressor role in kidney, brain, and other human cancers. Cancer Res 59: 798-802, 1999.

17. Eads CA, Lord RV, Wickramasinghe K, Long TI, Kurumboor SK, Bernstein L, Peters JH, DeMeester SR, DeMeester TR, Skinner KA and Laird PW: Epigenetic patterns in the progression of esophageal adenocarcinoma. Cancer Res 61: 3410-3418, 2001.

18. Darnton SJ, Hardie LJ, Muc RS, Wild CP and Casson AG: Tissue inhibitor of metalloproteinase-3 (TIMP-3) gene is methylated in the development of esophageal adenocarcinoma: loss of expression correlates with poor prognosis. Int J Cancer 115: 351-358, 2005.

19. Miyazaki T, Nakajima M, Faried A, Takita J, Sohda M, Fukai Y, Yamaguchi S, Masuda N, Manda R, Fukuchi M, Ojima H, Tsukada K and Kuwano H: An immunohistochemical study of TIMP-3 expression in oesophageal squamous cell carcinoma. Br J Cancer 91: 1556-1560, 2004.
20. Eads CA, Danenberg KD, Kawakami K, Saltz LB, Danenberg PV and Laird PW: CpG island hypermethylation in human colorectal tumors is not associated with DNA methyltransferase overexpression. Cancer Res 59: 2302-2306, 1999.

21. Eads CA, Lord RV, Kurumboor SK, Wickramasinghe K, Skinner ML, Long TI, Peters JH, DeMeester TR, Danenberg KD, Danenberg PV, Laird PW, Skinner KA, Kawakami K, Saltz LB, Blake C and Shibata D: Fields of aberrant CpG island hypermethylation in Barrett's esophagus and associated adenocarcinoma. Cancer Res 60: 5021-5026, 2000.

22. Blin N and Stafford DW: A general method for isolation of high molecular weight DNA from eukaryotes. Nucleic Acids Res 3: 2303-2308, 1976

23. Olek A, Oswald $\mathbf{J}$ and Walter $\mathrm{J}$ : A modified and improved method for bisulphite based cytosine methylation analysis. Nucleic Acids Res 24: 5064-5066, 1996.

24. Eads CA, Danenberg KD, Kawakami K, Saltz LB, Blake C, Shibata D, Danenberg PV and Laird PW: MethyLight: a highthroughput assay to measure DNA methylation. Nucleic Acids Res 28: E32, 2000.

25. Salmela MT, Karjalainen-Lindsberg ML, Puolakkainen $P$ and Saarialho-Kere U: Upregulation and differential expression of matrilysin (MMP-7) and metalloelastase (MMP-12) and their inhibitors TIMP-1 and TIMP-3 in Barrett's oesophageal adenocarcinoma. Br J Cancer 85: 383-392, 2001.

26. Jiang Y, Goldberg ID and Shi YE: Complex roles of tissue inhibitors of metalloproteinases in cancer. Oncogene 21: 2245-2252, 2002. 